\title{
A Qualitative Study of Understanding Clients' Relational Trauma
}

\author{
Wan-Chen Chen
}

\begin{abstract}
Relational trauma refers to an extreme fear of an individual that he/she feels a lack of control and helplessness because of being abandoned, neglected and bullied in earlydependency relationship. The individual could neither predict the end of a relationship nor escape from the relationship that he/she enters into a state of disconnection from others. The present study explored how relational trauma result in a pattern of rigid and distorted interpersonal relationship of an individual, and investigated its influence on individual's later interpersonal experience. Data was based on the depth interviews of a senior psychologist who conducted relational approach long-term psychotherapy and informed consent was obtained from the client. The psychologist provided the process of how the client started to talk about his relational trauma after their close counseling relationship was built. The psychologist was interviewed twice for around two hours each time and verbatim transcription was conducted after the interview. Independent-coder method was adapted to insure the reliability and validity of data analysis; furthermore, to deeply reflect the life experience of client in constructing relational traumatic process. Finally, suggestions for future research and practice are given accordingly, and the results provide educators with fundamental knowledge about clients' change.
\end{abstract}

Index Terms-Long-term psychotherapy, qualitative research, relational approach, relational trauma.

\section{INTRODUCTION}

Interpersonal trauma could be broadly defined as the traumatic ordeals developed after a person experienced or witnessed terrifying events in human interaction in which one feels frightened or threatened. The terrifying events include sexual assault, physical abuse or mentally abuse [1], [2] and the patterns of interpersonal trauma could range from one's personal experience to witness of others; furthermore, the perpetrator could be either a close person or a stranger, while the trauma might take place throughout one's life [3], [4]. In general, interpersonal trauma caused by a closer person may have a severe effect. Traumas not only include distinct physical abuse or sexual abuse, but also contain one's psychological harm of extreme fear, helplessness and frustration caused by oral and non-verbal message [5]. Some researchers used a more restricted way to define interpersonal trauma that interpersonal trauma refers to the rupture of a relationship bond when one's trust or faith in a close other is damaged through abandoned, neglected and bullied, followed by an extreme lost and distrust of the individual [6].

Manuscript received June 18, 2015; revised December 24, 2015. This work was supported in part by the Taiwan Ministry of Science and Technology under Grant103-2410-H-004 -087.

Wan-Chen Chen is with the Department of Education, National ChengChi University, Taiwan (e-mail: wan-chen@nccu.edu.tw).
In this respect, researchers try to explain how interpersonal trauma is developed under the perspective of "intimate dependency".

Dependence refers to the fundamental psychological needs of human beings, and serves as a linkbetween people and close other, and a key that links through the interaction of the world [7], [8]. People rely on the dependency with their primary caregivers in the early stage of development, and through the ongoing dependency, one's needs of being loved and cultivated, emotion, living and safety are fulfilled. This dependency between individuals and the caregivers is crucial as it provides individuals a sense of connection with their primary caregivers.

However, psychological trauma, which happened in early dependency, will bring individuals into intense conflict and confusion, and people struggling with psychological trauma may have nothing to rely on since then.Psychological trauma can become a particular challenge to individuals and directly impact their construction of personality; moreover, it will negatively affect a person as an adult, resulting in a difficulty to build and maintain future intimate relationship with others.

To differentiate traumatic experience from other kinds of trauma in essence, we used the term "relational trauma" to specifically refer to the psychological trauma caused by early intimate dependency. From the perspective of how a relational trauma is developed, the definition of relational trauma is framed based on the concept of dependency. As a whole, relational trauma is defined as an extreme fear of individual that he/she feels a lack of control and helplessness because of being abandoned, neglected and bullied during early dependency.

Relational trauma will result in an extreme fear in which an individual enters into a state of disconnection from others. We could know the feelings of relational trauma from a client's description that people with relational trauma unintentional re-experience the ordeal and disconnection through thoughts and memories, and they try to avoid people or situations that were associated with the traumatic event because these might in reminding them of the trauma.

\section{IMPACT OF RELATIONAL TRAUMA ON INDIVIDUALS}

\section{A. Impact of Relational Traumatic Experiences on Individuals}

In Bowlby's attachment theory [9], [10], one's internal representation is developed from the interaction one has with the world, important others, and the self. One's cognitive-emotional schema is internalized based on the quality of early attachment and will affect the behavioral 
pattern of one's expectation, feelings and interpersonal relationship. The impacts of relational trauma on individuals were discussed separately into three parts; namely, perspective towards self, perspective towards others, and one's main interpersonal relationship pattern.

\section{B. Perspective toward Self (Self-representation)}

Attachment is critical for fostering one's self-representation and could be defined as a lasting psychological connectedness between infants and their primary caregivers. The availability and responsiveness of the primary caregivers, from which the infants use as a safe base to explore, would transfer into understanding and expectation, which, may internalize into one's perception toward the self.

Individuals with positive self-representation may feel secure, while individual with negative self-representation may feel disturbed and uneasy. People develop negative self-representation especially after they experience relational trauma. Relational trauma, whether caused directly by physical assault, psychological, oral abuse, or indirectly transferred by caregivers, can have negative physical and psychological impacts on individuals [11], [12]. Children exposed to domestic violence will develop a negative self-representation of helplessness and worthlessness. Occasional outbursts of aggression may occur as a mechanism to some children to maintain their safeties in response to the perceived threats [13]. Individuals of sexual abuse often re-experience the intrusive memories of events, accompanied by a feeling of worthless and guilty. They tend to construct a negative self-representation that they don't deserve building a healthy interpersonal relationship with others [14]. Thus, a negative self-representation of being helpless and guilty is formed in the context of the initial child-caregiver relationship.

\section{Perspective toward Others (Other Representation)}

Other representation refers to the subjective and internal psychological impression one develops of others when interacts with other people. Bowlby [15] stated that individuals with negative interval working model are likely to develop a negative expectation of others. When individuals experiencing their important others as emotionally responsive, trustworthy and consistent, a positive explanation of others will be made. Conversely, experiences of rejection, and unreachable will lead to the construction of a negative other-representation [16].

Relational trauma one experiences will have a negative effect on individuals' impression of important others, resulting in an insecure and unstable impression of other people [17]. Children who witness domestic violence tend to develop an insecure other-representation based on the instable environment where they have grown up. Children with sexually abuse repeatedly relive the pain through memories of the trauma, fear and helplessness continues, becoming so strong that they view others as terrifying and threatened [11]. For the children who are sexually abused by their close other, the discovery that someone you trust has sexually abused you is accompanied by extreme pain, during which the loss of trust is ruined, result in an inconsistent others-representation [18]. One's negative impression of others as inconsistent, unstable and insecure increases the likelihood a person will suffer negative emotions that include not only distrust, deprived and insecurity but also a tough time trusting others.

\section{Rigid and Distorted Interpersonal Relationship brought by Relational Trauma}

Relational trauma victimizers are more likely to feel alienate, distrusted and insecure. These characteristics are carried into new situations, thereby fostering their avoidance behaviors in real life situations. To avoid re-experiencing relational trauma, victimizers will develop a pattern of distorted and rigid interpersonal interaction, which may have a negative long-term effect on their relationship.

Collin and Read [19] stated that one's self-representation and interpersonal script were developed through the interaction with important others and these patterns will generalize across other relationships to satisfy one's social and emotional needs. Individuals suffered from different relational traumasform their insure attachments based on the negative self-and-others representation. When confronting interpersonal conflicts, these trauma survivors tend to interpret conflicts as "separation" or "rejection" in order to satisfy their internal needs. They use behaviors including patronage, avoidance, distorted thoughts, dissociation, denial, self-paralysis, suppression, and attack others to relieve their pressures [20]-[22] and are more likely to utilize isolated, aggressive, and ingratiatory strategies to cope with interpersonal relationships [23], [24]. People with relational trauma would therefore form a distorted interpersonal relationship with others.

Furthermore, empirical studies have found that victims of relational trauma tend to unconsciously build a relationship with someone who is likely to become a violent perpetrator. The victim becomes accustomed to linking mistreatment with a sense of safety and developmentally been arrested in the negative cycle in which the victims may feel a sense of security [25]. Trauma victims have remained stuck in the past with their traumas, and, consciously or unconsciously, acted the roles of being bullied, and threatened. The interpersonal mechanism they developed from the past will become rigid and play out repeatedly in their later relationships. Therefore, relational trauma ossifies victimizer's original interpersonal patterns.

Relational trauma would continually affect one's later interpersonal relationship through a pattern of distorted and rigid interpersonal relationship. One primary interpersonal difficulty most clients have is that they are usually trapped in a relationship. Although most clients want to change their difficulties, they are unable to control and are lack of positive interpersonal experiences.

\section{METHOD}

\section{A. Participants}

The participants included a senior male psychologist (52 yrs) who had specialized in long-term psychological treatment and had successfully treated several clients with 
childhood interpersonal trauma, and a male client (43 yrs), who had experienced interpersonal trauma during his childhood and had actively chosen to receive psychotherapy regularly as adult for nine years.

\section{B. Data Sources}

Interviews. All of the interviews were conducted in Mandarin. The psychologist was interviewed twice for around two hours each time and the interview was semi-structured. The researcher generated the interview questions based on previous literature regarding interpersonal trauma.

Transcription. Each interview was transcribed verbatim. The clients agreed to being discussed by his psychologist and reviewed his interview transcript for additional corrections and feedback until he was satisfied with the accuracy of the transcriptions.

Field notes and reflexive journals. The researcher kept detailed field notes and reflexive journals throughout the interview and data analysis procedures. The researcher documented these discussions to facilitate the understanding of the researchers' own assumptions and biases, and to assist with later analyses.

\section{Procedure}

Data collection. The senior psychologist works in the same community as the researcher and was invited to share his plentiful treatment experience regarding clients with interpersonal trauma. At the beginning of the interview, informed consent was discussed in detail with the client, with special attention paid to confidentiality and the right to withdraw from the study at any time. After the participants consent to being discussed, the interview process with the psychologist was audiotaped.

Data analysis. Analyses began after the transcribed interviews were reviewed by the psychologist and his clients. The consensual qualitative research method [26] is characterized by the following three steps. First, each research team member independently assigned a data segment to various domains and coded the data into domains. Then, the research team members discussed differing opinions regarding their interpretations of the data until a consensus was reached that consisted of the core ideas. Finally, a conceptual model was developed to diagram the relationship among the domains to achieve a comprehensive understanding of the issues discussed.

\section{Trustworthiness}

The trustworthiness of the findings was established according to various criteria [27]. The credibility of the findings was demonstrated through reconstructing and re-contextualizing the data using peer discussion. The main researcher is a faculty member and senior registered psychologist with 15 years of working experience. The transferability of the findings was enhanced by providing a detailed description of the participants and results. The dependability of the findings was achieved by keeping detailed memos and reflexive journals so that the participants' perspectives are able to speak for themselves.

\section{RESUlTS}

Client (CL) attended the therapy once a week. After ten months, CL started to talk about his traumatic experiences in the past.

\section{A. Loss of Bonding Resulting from Traumatic Experiences}

During the $40^{\text {th }}$ therapy session, CL talked about an extreme painful experience.

CL mentioned, "When I was in grade 2, I wet on my bed. My mom was so angry that she crammed the diaper in my mouth. She humiliated me and laughed at me, then she started to beat me badly. I am so afraid that I didn't know when would she stop. Finally, she stopped and left. I sit huddled up in the corner and waited until I am not afraid. I feel tired and pain all over, and my image became clearer. I felt so confused about whether she was the one who beat me. She humiliated me and beat me so heavily as she was crazy. Is that really my mom? Am I really so nasty? She said she did these things for me, but she sometimes really treat me well. This is so confused. I can't even know who she is. The more I thought, the more confused I became. I wanted to stop thinking but just I can't. I can't breathe, I felt fuddle-headed and overwhelmed. I feel like I am going be mad and crash. Then suddenly, everything seemed to be far away from you and every feeling disappeared. Everything is irrelevant to you and you are alone. After I grown up, it is so terrible to feel that you are disconnected with others."

CL also discussed relational traumatic experiences from his childhood. He recalled that his father was constantly busy with work and his mother was the primary caregiver. However, CLdreaded his mother's emotional instability and felt that he possessed no sense of control over his own life. He has a brother, who is two years older than him. CL described that his brother seldom made mistakes and that they were not close. Co had asked CL to bring several childhood photographs. In one of the photographs, the family's old house is in the background and CL, who was four years old at the time, looked at the camera with a calm face, while his brother smiled broadly. CL said he had no recollection of the scenes in the photograph and was confused by his own image. CL's childhood memory was blank and it was difficult to recall about his childhood experience.

\section{B. "Confusion between Caregiver and Victimizer" Resulted from Trauma}

During the $55^{\text {th }}$ therapy session, CL mentioned his ambivalent feelings toward his mother during childhood.

CL complained about his mother, "If you are my mother, you should love me, not hurt me. But you hurt me continually. If you are not my mother, then I should not be living with you, and the name on the household registration should not be yours, but it is. I do not understand; if you are my mother, why did you hurt me? I cannot understand!" A was extremely helpless, "When will I begin to understand?"

According to CL, his trauma derived from his mother's attacks. The pain and fear generated from those attacks exceeded what his mental age at that time could endure, and he lacked the sense of control to end the attacks and pain. However, CL's mother was the one who cared for him the 
majority of the time and treated him very well. The relationship dependency between CL and his mother generated intense conflicts and confusion, and this relationship confusionperplexed $\mathrm{CL}$ in his future intimate relationships with others.

\section{C. "Separation" and "Maintenance" Determined by Early Decisions}

\section{1) To maintain feelings of guilt and to please others}

During the $70^{\text {th }}$ therapy session, CL mentioned his interactions with his mother.

"I offered all my money to my mother and still she did not accept me. Whenever she complained, I exerted every effort to please her, but still worried that I did not perform good enough. When my mother needed my help, or when I knew I should be empathetic with her because she worked extremely hard, these were the time when I felt she was the closest thing to being an ideal mother."

The confusing relationship between CL and his mother derived from the confusion between caregiver and victimizer. He used "separation" to manage his mother's confusing and conflicting image. Because of a sense of guilt, he strived to care for his mother; however, he encountered disappointment when he attempted to excessively please her, and feelings of confusion were the result. When he recovered his emotions, he would again attempt to please his mother out of guilt, and would quickly forget his disappointment in her. Therefore, his disappointment and guilt and their relations to his mother cannot be discussed together.

\section{2) Un-integrated images because of the continued emotional detachment}

During the $73^{\text {th }}$ therapy session, Co asked CL about his relationship with his mother.

Co: "You mentioned that your mother did not treat you well. Can you expand upon this?"CL: "I once told her that my classmate received a pencil case and that mine was fairly old! She started to scold me and said I should be contented with that I had, and that I knew nothing of her toil. She raised her voice! I did not know how to respond. I just hoped that her temper would soon improve! I just stand there silently while she asked in anger whether I was disobeying her. She then was in a rage and beat me violently as if she was trying to beat me to death... I was scared and did not know what to do. " CL experienced body ticks and broke down in tears.

After CL calmed down, he talked about incidents he encountered at his company, and continued to talk until our interview ended. One week later, when CL entered the interview room...Co offered to mention the interview content from the previous week. A indicated that he had only several memories about the talk that his mother was angry with him, however, he couldn't remember what she was like when she was angry. He cared little for the issue and had only a faint memory of it.

"Inattentiveness" was another crucial technique that CL used to respond to his traumatic experiences. He completely disconnected from how his emotions influenced him by being inattentive. Because he continually used emotional detachment and inattentiveness as coping strategies, image integration about himself and others was difficult. He felt that his life experience was fragmented and lacked consistency.

\section{Responses to Trauma}

1) To maintain a high sense of control to avoid the recurrence of trauma

In the $69^{\text {th }}$ therapy session, CL mentioned his imagination of his future partner. "I hope my future partner will be as innocent as Snow White, who is simple and unsophisticated. I always tell myself not to accept girls if they are from wealthy family backgrounds and well educated because I think it would be unsafe. Actually, I feel I am inferior, I am afraid that I would not be good enough for those women and that they would despise me! I cannot accept women who do not provide maternal love! I think it is necessary to have several specific standards when choosing a partner. What would I do if I am in love with a woman but she despises me? "CL mentioned at the end, "Well, how should I live if my wife is just like my mother?"

To gain an increased sense of control and to avoid the recurrence of trauma, CL established standards for selecting a future partner, which was a preventative measure. CL also controlled his dependency on his partner, and had a crucial belief that if he did not consider them important, then he would not need to worry about potential consequences arising from his dependence on them.

\section{2) Emotional detachment and inattentiveness}

The day before the $85^{\text {th }}$ therapy session, CL's fears reoccurred.

CL mentioned that when he casually reminded his girlfriend to tidy her messy room, his girlfriend was suddenly enraged and snapped back at him, "You complain about my laziness just like my mother does!" His girlfriend suddenly lost control, banged on the wall, and left the house. CL followed her until she stopped on the street. When she calmed down, the two returned to his girlfriend's house.

When his girlfriend lost control and banged on the wall, CL was terrified and thought, "I have no idea what will happen next!" He could maintain only complete focus on how the incident had developed. As his girlfriend gradually calmed down, CL's tension was reduced. By this time, he was too exhausted. "How many times will such incidents occur? Should I break up with my girlfriend?" CL was too exhausted to predict what would occur next.

When CL lay on his bed that night, he thought about the incident and found it difficult to tolerate; he felt that his affection for his girlfriend had decreased. Unlike before, this time he attempted to maintain his affection for her, but could not maintain it for a long period of time. He was fearful, felt helpless, and cried. Although his fear was intense, his affection for his girlfriend gradually decreased... When CL awoke the next day, he was tired and could not concentrate. He felt detached. A indicated in the interview that he feels a sense of distance when he talks about the incident.

Emotional detachment and inattentiveness continued to be the intense negative emotions that CL experienced; particularly, he often used these methods to manage his relationship anxiety. Although CL could face his anxiety more easily after a year and a half of counseling, and had attempted to correct his inattentiveness, his intense fear correlated to trauma recurrence continued to be present. 


\section{CONCLUSION}

The current study explored how the client with relational trauma talked about himself during psychotherapy. The qualitative data were obtained by a psychologist through interviews with one client, who subsequently reviewed and approved the transcripts. Qualitative studies, such as the current investigation, can provide a holistic, naturalistic, and detailed description of how this client copes with his relational traumas[28]. This study expands our understanding of the highly dynamic coping processes and outcomes of the client. First, with regard to symptoms of dealing with relational traumas, this study showed that it is difficult for the client to discuss traumatic experiences as he has been too anxious or depressed, which may have caused his memories to become blank and unclear. Second, regarding the state of meaninglessness, the client identified with a state of complete emptiness or numbness, which provided them with the space to make the traumatic experience less painful. Third, in the case of the defense of a sense of control, the client tried hard to use either avoidant or distractive coping strategies to gain a certain level of control over their lives, though these methods led to ineffective long-term adjustment outcomes. Fourth, concerning expectations of safe and dependent relationships, the unfinished desire for intimate relationships motivated the client to repeat the original interpersonal models. In the repeated models, both the maintenance of symptoms and the experience of contradictory emotions were symbols that represented the client' desire for change. Finally, with regard to the emergence of important relationships in reality, the client actively chose to enter psychological treatment to fulfill their unfinished needs.

The findings of this study also underscore the concept that relational traumas shape the client's specific personality functions. These personality functions helpthe client adapt to life, but they also impede change, resulting in a difficult situation in which clients need to change, but are unable to [29]. Current interpersonal difficulties are the primary motivation for the client who chooses to enter into therapeutic relationships. However, past relational traumas has changed the client's internal psychological states as a response to the influence of the traumatic stimuli, and as an attempt to control the interference of these stimuli on the client. These response methods develop into habits that the client used to deal with external information. Although these methods accomplish the initial goal of control, they become an impediment to the client who is seeking change when facing future difficulties.

The current study has significant implications for the practice of psychological treatment. The process of psychological treatment changes the original closed system of escaping from harm and provides clients with an opportunity to face their trauma. Clients start to learn to rely on the therapist. Yet when dependence anxiety becomes increasingly intense, clients react to the dependent anxiety. Typically, clients control their dependence on the therapist to reduce the dependence anxiety. Methods that clients used to control their dependence on the therapist include decreasing their personal investment in talks with the therapist, increasing their resistance to the therapist's suggestions, and avoiding the expression of their personal needs. These methods are used to control the perceived "influence" of the therapist. Clients could additionally avoid recognizing the importance of the therapist to them. Clients act emotionally detached and avoid any topic that could reflect that they place importance on the therapist. Clients consciously attempt to avoid or ignore the recognition that the therapist is important to them to reduce their dependence anxiety. The present study suggests that these testing behaviors represent clients' desire for change. Therefore, it is crucial that therapists remain stable and create a safe working alliance.

\section{ACKNOWLEDGMENT}

Thank you to my close colleague, Guo-Ching $\mathrm{Wu}$ and my excellent graduate students, Chen-Huei Huang and Shou-Chun Chiang who have consistently motivated and assisted me to finish this work.

\section{REFERENCES}

[1] C. L. Bright and S. Bowland, "Assessing interpersonal trauma in older adult women," Journal of Loss and Trauma, vol. 13, no. 4, pp. 373-393, 2008.

[2] W. A. Wysoczańska and A. Kuczyńska, "Interpersonal trauma and its consequences in adulthood," Cambridge Scholars Publishing Psychological Bulletin, vol. 99, pp. 66-77, 2010.

[3] L. S. Elwood, N. L. Williams, B. O. Olatunji, and J. M. Lohr, "Interpretation biases in victims and non-victims of interpersonal trauma and their relation to symptom development," Journal of Anxiety Disorders, vol. 21, pp. 554-567, 2007.

[4] J. Scott, D. Chant, G. Andrew, G. Martin, and J. McGrath, "Association between trauma exposure and delusional experiences in a large community-based sample," British Journal of Psychiatry, vol. 190, pp. 339-343, 2007.

[5] P. Nishith, M. B. Mechanic, and P. A. Resick, "Prior interpersonal trauma: The contribution to current PTSD symptoms in female rape victims," Journal of Abnormal Psychology, vol. 109, no. 1, pp. 20-25, 2000.

[6] J. H. Findling, S. C. Bratton, and R. K. Henson, "Development of the trauma play scale: An observation based assessment of the impact of trauma on the play therapy behaviors of young children," Clinical Pediatrics, vol. 49, pp. 443-449, 2006.

[7] H. A. Murray, Clinical Studies of Personality, New York, NY: Harper \& Row, pp. 615-641, 1955.

[8] M. Tait, "Dependence: A means or an impediment to growth?" British Journal of Guidance and Counselling, vol. 25, pp. 17-26, 1997.

[9] J. Bowlby, Attachment and Loss, New York: Basic Books, 1980.

[10] J. Bowlby, Attachment and Loss, New York: Basic Books, 1982.

[11] D. Finkelhor and A. Browne, "The traumatic impact of child sexual abuse: A conceptualization," American Journal of Orthopsychiatry, vol. 55, no. 4, pp. 530-541, 1985.

[12] M. Bradley, "Elder abuse: Caring for older people," British Medical Journal, vol. 313, pp. 548-550, 1996.

[13] E. A. Waites, "Trauma and survival: Post-traumatic and dissociative disorders in women," American Journal of Clinical Hypnosis, vol. 36, no. 4, pp. 293-294, 1993

[14] P. Parks, Parks Inner Child Therapy, London, England: Souvenir Press, 1994.

[15] J. Bowlby, "Attachment and loss," Anxiety and Anger, New York: Basic Books, 1973.

[16] K. Bartholomew and L. M. Horowitz, "Attachment styles among young adults: A test of a four category model," Journal of Personality and Social Psychology, vol. 61, pp. 226-244, 1991.

[17] K. D. Rudolph, W. Troop-Gordon, and M. Flynn, "Relational victimization predicts children's social-cognitive and self-regulatory responses in a challenging peer context," Developmental Psychology, vol. 45, pp. 1444-1454, 2009.

[18] A. Browne and D. Finkelhor, "Impact of child sexual abuse: A review of the research," Psychological Bulletin, vol. 99, no. 1, pp. 66-77, 1986.

[19] N. L. Collins and S. J. Read, "Cognitive representations of adult attachment: The structure and function of working models," Advances in Personal Relationships, pp. 53-90, 1994. 
[20] J. Briere, "Methodological issues in the study of sexual abuse effects," Journal of Consulting and Clinical Psychology, vol. 60, pp. 196-203, 1992.

[21] M. B. Levy and K. E. Davis, "Love styles and attachment styles compared: Their relations to each other and to various relationship characteristics," Journal of Social and Personal Relationships, vol. 5 , no. 4, pp. 439-471.

[22] M. C. Pistole, "Attachment in adult romantic relationships: Style of conflict resolution and relationship satisfaction," Journal of Social and Personal Relationships, vol. 6, pp. 505-510.

[23] C. Meesters and P. Muris, "Perceived parental rearing behaviors and coping young adolescents," Personality and Individual Differences vol. 37, no. 3, pp. 513-522, 2004

[24] U. Wolfradt, S. Hempel, and J. N. V. Miles, "Perceived parenting styles, depersonalization, anxiety, and coping behavior in normal adolescents," Personality and Individual difference, vol. 34, no. 3, pp. 521-532, 2003.

[25] D. P. Celani, "Applying fairbairn's object relations theory to the dynamics of the battered woman," American Journal of Psychotherapy, vol. 53, no. 1, pp. 60-73, 1999 .
[26] C. E. Hill, S. Knox, B. J. Thompson, E. N. Williams, S. A. Hess, and N. Ladany, "Consensual qualitative research: An update," Journal of Counseling Psychology, vol. 52, pp. 196-205.

[27] S. L. Morrow, "Quality and trustworthiness in qualitative research in counseling psychology," Journal of Counseling Psychology, vol. 52, no. 2, pp. 250-260, 2005

[28] R. S. Lazarus, "Toward better research on stress and coping," American Psychologist, vol. 55, pp. 665-673, 2000.

[29] E. Teyber and F. H. McClure, Interpersonal Process in Therapy: An Integrative Model, Belmont, CA: Thomson Brooks Cole, 2010.

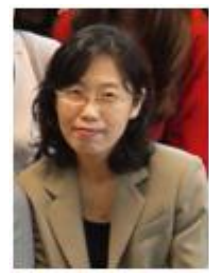

Wan-Chen Chen was born in Keelung, Taiwan in 1974. She received her doctor's degree in educational psychology from the University of Texas at Austin. She has been published one book The Framework of Relational Approach Counseling: Theory and Practice. The core concept of this research was derived from that book. 